\title{
EL PROYECTO EPRODESERT. CAMBIOS DE USO DEL SUELO Y MORFODINÁMICA EN EL NORDESTE DE ESPAÑA
}

\author{
Johannes B. RIES \\ Institut für Physische Geographie, Universität Frankfurt, Alemania \\ Manuel SEEGER e Irene MARZOLFF \\ Institut für Physische Geographie, Universität Freiburg, Alemania
}

\begin{abstract}
Resumen: El proyecto EPRODESERT (Evaluation of Processes Leading to Landdegradation and Desertification under Extensified Farming Systems) estudia el complejo sucesión de vegetación/morfodinámica/niso del suelo en Aragón. Un primer análisis socioeconómico considera las razones y la dinámica del abandono de tierras. Utilizando fotos aéreas a gran escala, tomadas desde un zeppelin aerostático teledirigido y combinándolas con una clasificación de la morfodinamica y la vegetación, se estudia detalladamente la evolución de los campos abandonados. Con métodos experimentales se cuantifican los procesos de infiltración, escorrentía y erosión eólica. Destaca como primer resultado el diverso comportamiento ante la precipitación de los campos abandonados de diferente antigüedad y de las costras edáficas que los cubren.
\end{abstract}

Palabras clave: Degradación, dinámica vegetal-morfodinámica-uso del suelo, fotografía aérea a gran escala, erosión.

\begin{abstract}
The project EPRODESERT (Evaluation of Processes Leading to Landdegradation and Desertification under Extensified Farming - Systems) investigates the vegetation succession/morphodynamic/land-use complex in Aragón (NE Spain). Socioeconomic investigation studies the reasons and the dynamics of land-use change. The evolution of the abandoned fields is surveyed using large scale aerial photographies taken from a hot air blimp and combining them with a monitoring of geomorphodinamics and vegetation. Experimental studies about infiltration, runoff and eolic erosion cuantify the processes. First results mark the different behaviour, regarding rainfall, of fields with diferent time of abandonment and the different crust types.
\end{abstract}

Key words: Degradation, dinamic of vegetation-morphodynamic-land-use, large scale aerial photography, erosion. 


\section{INTRODUCCIÓN}

El proyecto EPRODESERT (Evaluation of Processes Leading to Landdegradation and Desertification under Extensified Farming Systems) se está llevando a cabo desde abril de 1995 por los Departamentos de Geografía Física de las Universidades de Friburgo y Frankfurt (Alemania). El estudio se centra en el análisis de la erosión, la sucesión de la vegetación y la degradación de áreas no cultivadas entre la Cordillera Pirenaica y la Depresión del Ebro.

La explotación y sobreexplotación durante más de mil años de la zona semiárida del sector central de la Depresión del Ebro son la causa de erosión y desertificación en este área. Los encinares y otras formaciones arbóreas han sido sustituídas en su mayoría por cultivos o por formaciones esteparias, siendo las partes altas y medias de las laderas las que están más afectadas por esta degradación.

La situación en el Prepirineo es parecida: talas rigurosas y sobrepastoreo han deteriorado desde época romana los bosques de la zona. También la cadena central pirenaica fue utilizada intensamente desde el siglo décimo como zona de pastoreo; el límite del bosque ha sido rebajado considerablemente, con lo que la morfogénesis natural ha sido alterada.

En toda el área de trabajo domina hoy, tras siglos de explotacion agrícola y pastoreo intensivo, la transformacion hacia explotaciones extensivas. Los objetivos de este proyecto son comprender la relación entre vegetación/morfodinámica/uso del suelo y evaluarla con vista al uso sostenible de los recursos naturales.

\section{ÁREAS DE TRABAJO}

Se han escogido cinco áreas de trabajo a lo largo de un transecto paisajístico entre el Pirineo Central y la Depresión del Ebro. Un área de uso ganadero, bajo del límite natural forestal (Sierra de Aísa, piso subalpino), dos en los valles longitudinales y transversales, anteriormente sometidos a un uso agrícola intenso (Arnás, en el Valle de Borau, y Bentué, en el valle de Rasal), tn área en la cara meridional del Prepirineo, en un antiguo viñedo del piso colino (Sabayés, al pié de la Sierra del Aguila) y una última en el sector central de la Depresión del Ebro, incluyendo cultivos abandonados de diferente antigüedad (María de Huerva, en el valle del Huerva) (Fig.1). 


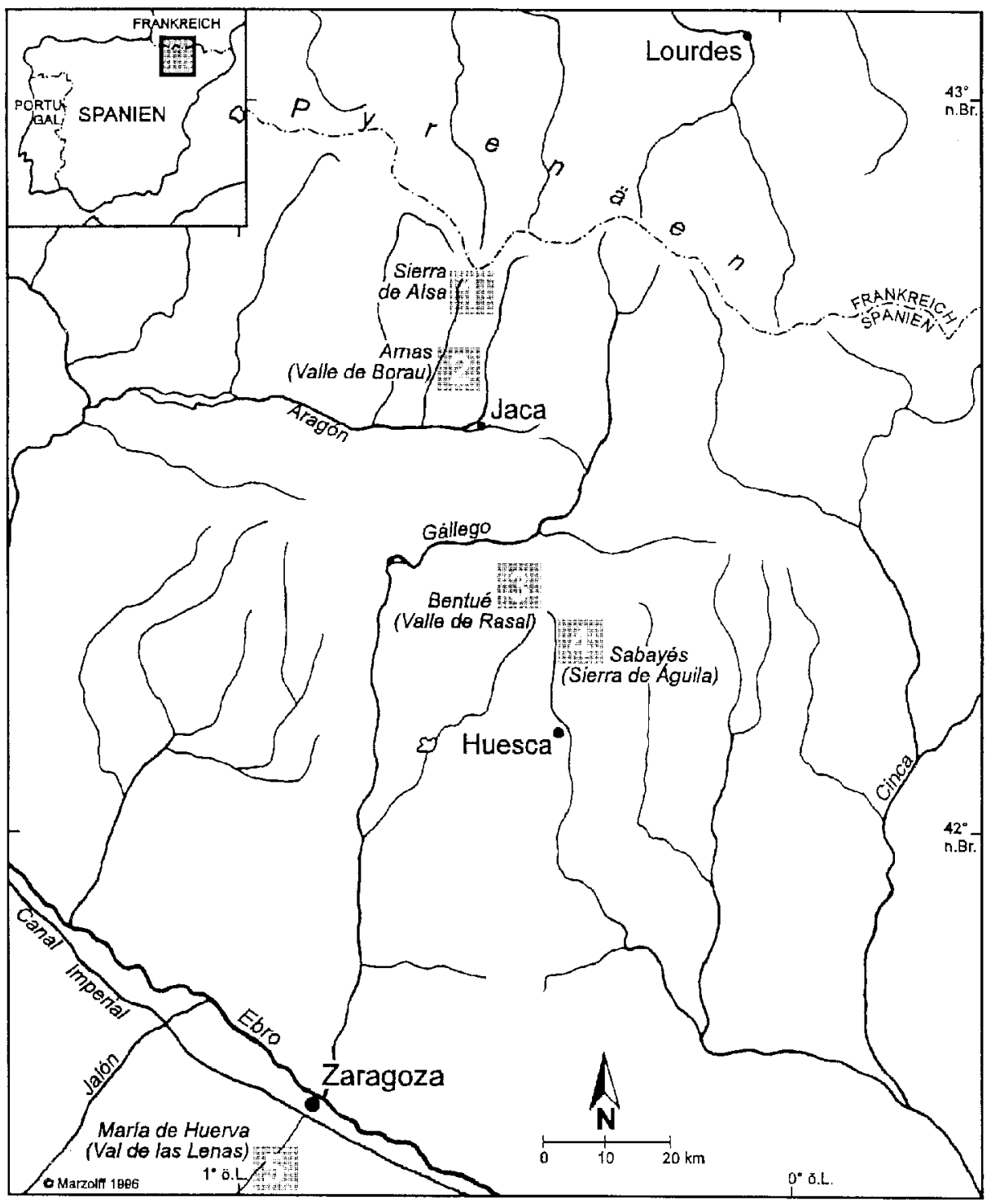

Figura 1.- Localización de las áreas de trabajo. 


\section{METODOLOGÍA}

\section{Bases socioeconómicas y socioculturales del abandono de tierras y de la extensificación de los usos del suelo}

El estudio de las bases socioeconómicas, políticas y culturales del abandono de tierras es el fundamento de la comprensión de la evolución del paisaje. Han sido recogidos y evaluados datos estadísticos sobre la evolución demográfica y económica y sobre la dinámica de uso del suelo. Se ha generado una base de datos sobre todas las áreas de trabajo, las provincias y la comunidad autónoma de Aragón que documentan el proceso de extensificación de la actividad agraria y sus diferenciaciones espaciales. Estos datos se han combinado con encuestas semiestandarizadas y conversaciones con los afectados y con funcionarios de diferentes organismos administrativos, en un intento de comprender los motivos y las contradicciones del desarrollo de la zona y pronosticar, en la medida de los posible, la evolución del uso del suelo.

\section{Areas de muestreo y asignaciones de valores}

La investigación del complejo vegetación/morfodinámica/uso del suelo se basa en áreas de muestreo de $36 \times 24 \mathrm{~m}$ en cultivos abandonados y pastos representativos de cada sector. Estas áreas están cubiertas durante las etapas de muestreo por una red de referencia integrada por 3456 retículas, de $50 \times 50 \mathrm{~cm}$, de las que se obtiene información relacionada con la superficie de cubrimiento vegetal -desde $\leq 5 \%$ de cubierta hasta $\geq$ $90 \%$, con las formas de vida -"nidos", "rosetas", "reptantes", "geófitos" y "terófitos"y con la morfodinámica -desde retículas "sin erosión", "erosión difusa leve", "erosión difusa fuerte", "erosión en surcos" hasta aquéllas en las que se registra "acumulación" de material-.

Las áreas de muestreo son las áreas de referencia para el monitoring con fotos aéreas. Con ellas se pretende seguir la evolución de la morfodinámica actual de los campos abandonados durante varios años, y constituyen la base para la interpretación de las imágenes tomadas desde el "blimp", tal y como se detalla bajo el siguiente epigrafe. (blimp)

Muestreo basado en fotos aéreas tomadas con un globo aerostático

La evolución de procesos morfodinámicos y variaciones a pequeña escala de la cobertura vegetal son difíciles de documentar con fotos aéreas tomadas desde aviones o con imágenes tomadas desde satélites, siendo imposible contar con vuelos de cada uno de los eventos agresivos de precipitación. Por ello, se ha desarrollado para este proyecto un globo aerostático o "blimp" (Fig. 2) como plataforma para dos cámaras fotográficas convencionales. Con ellas se toman imágenes en color e infrarrojas. 
Durante un vuelo se pueden realizar fotos desde unos $25 \mathrm{~m}$ hasta $400 \mathrm{~m}$ de altura, obteniéndose imágenes de escalas entre 1:500 y 1:14000.

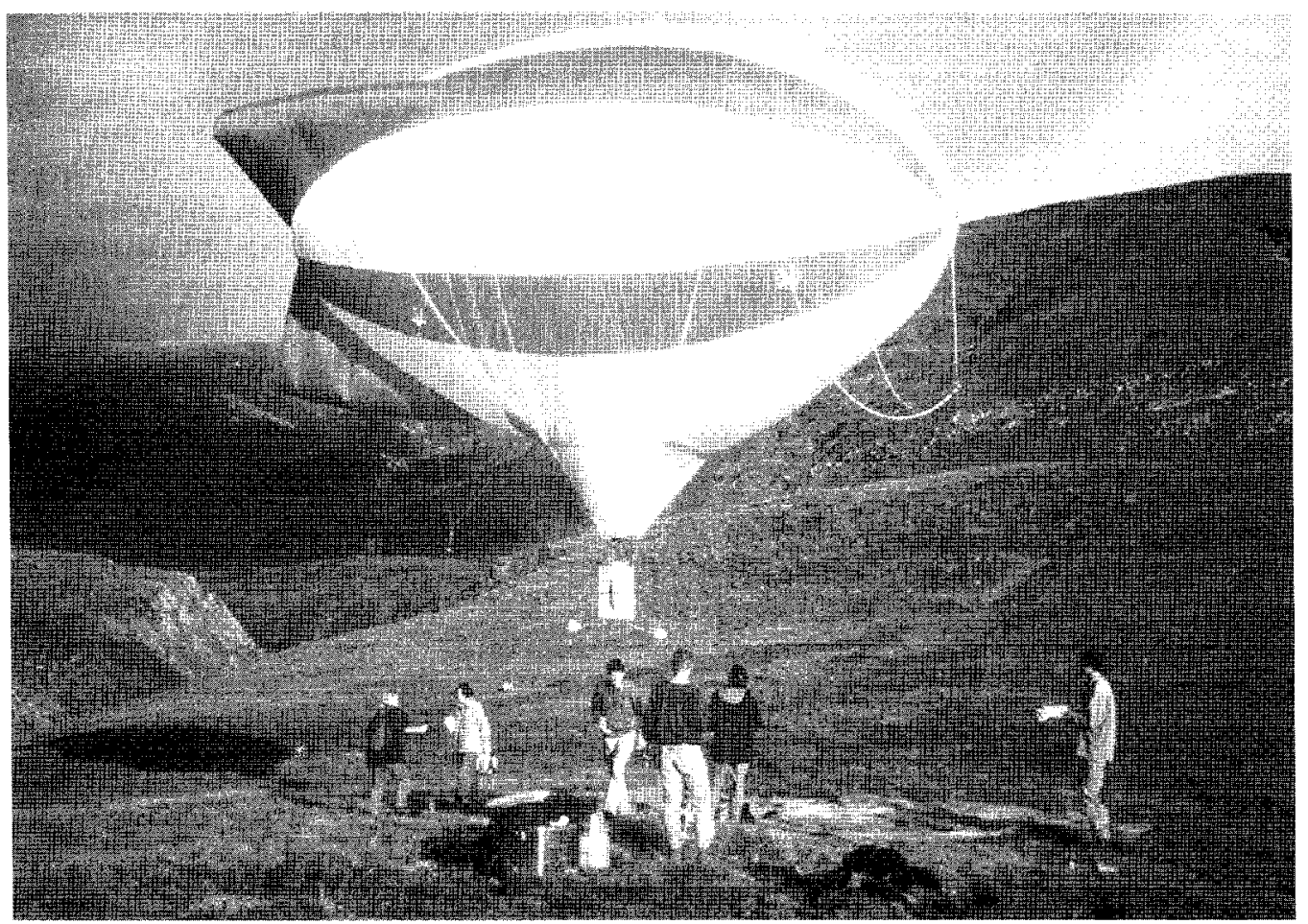

Figura 2.- Blimp utilizado en el poryecto EPRODESERT.

Desde octubre de 1995 hasta agosto de 1997 existen secuencias fotográficas de hasta cuatro fechas diferentes, que permiten seguir y documentar la evolución morfodinámica y de la cobertura vegetal a lo iargo de varios años y en distintas estaciones - un monitoring aéreo a gran escala-. Las imágenes son digitalizadas para el consiguiente tratamiento digital y su análisis en un Sistema de Información Geográfico. Simultáneamente, las imágenes han sido interpretadas de un modo convencional para documentar los procesos geomórficos y las formas relacionadas con ellos. Uno de los objetivos principales se basa en investigar las posibilidades que ofrece la utilización de fotos aéreas a gran escala en el estudio de problemas geomorfológicos. 


\section{Estudio de los suelos}

El suelo constituye la base para el desarrollo de la vegetación y el medio directamente afectado por la erosión. Por lo tanto, su estudio esta enfocado hacia el papel jugado por los suelos en la sucesión de la vegetación y su comportamiento en relación con los agentes erosivos.

En primer lugar han sido estudiados y muestreados varios perfiles en campos de diferente edad de abandono en las áreas de trabajo. Además, se tomaron varias muestras de los $10 \mathrm{~cm}$ superiores del suelo para analizar el contenido en nutrientes y la composición química de extractos acuosos. Además se han analizado en los perfiles las características hidráulicas, es decir la conductividad y la retención de agua. También se han realizado estudios sobre la estructura y el comportamiento de los suelos, cuya metodología presentaremos en los siguientes capítulos.

\section{Estudio de costras edáficas}

La presencia de costras edáficas parece ser, especialmente en la Depresión del Ebro, uno de los factores principales que controlan la escorrentía y la erosión. En un primer paso, han sido diferenciadas costras de distinta edad, desde las localizadas en campos labrados tres meses antes del análisis, hasta otras de seis años de antigüedad. También se han clasificado, según su posición morfológica, en costras sobre surcos, sobre terrones y sobre abanicos de sedimentación. Se han trabajado láminas delgadas, completando el estudio con um análisis químico y granulométrico de las diferentes estructuras.

\section{Experimentos sobre la infiltracića, la escorrentía y la erosión}

De forma paralela a las técnicas descritas, se han realizado simulaciones en el campo para recoger $y$, en la medida de lo posible, cuantificar los parámetros que causan la desertificación y degradación. Así se han diseñado experimentos que recogen numerosos datos sobre la infiltración, la escorrentía y la erosión.

Para la evaluación de la infiltración se han utilizado dos clases de infiltrómetros, uno de doble anillo siguiendo el modelo de Bork y otro de anillo simple según Hills. Para la simulación de lluvia se modificó el simulador diseñado en el Instituto Pirenaico de Ecología de Zaragoza. Las condiciones de simulación están basadas en la producción de una precipitación de $40 \mathrm{~mm} / \mathrm{h}$ durante 30 minutos, de la que se controlan la escorrentía y el sedimento sólido y en solución producidos cada 5 minutos. 


\section{RESULTADOS}

La presentación de resultados no pretende ser definitiva. Además, el estudio de alguna de las variables no está concluido, de modo que ofrecemos resúmenes parciales y algunos ejemplos.

\section{Bases socioeconómicas y socioculturales del abandono de tierras y de la extensificación de los usos del suelo}

Se ha escogido como ejemplo el área test de Sabayés, aunque su situación geográfica le reste cierta representatividad. La evolución demográfica indica un máximo de población en los años 30 (más de 250 habitantes), que tras concluir la Guerra Civil empieza a disminuir hasta alcanzar un mínimo de 18 habitantes en 1994. En 1 a actualidad se mantienen 6 casas constantemente habitadas. Un gran número de las restantes viviendas han sido restauradas y son habitadas de forma periódica o estacional.

Los equipamientos son deficientes; los únicos lugares públicos son la iglesia y el bar, el cual a la vez sirve de centro social. Al pasar el municipio a formar parte del de Nueno desapareció el Ayuntamiento y lo mismo ha sucedido con la escuela primaria del pueblo. Así, la población restante o esporádica de Sabayés está ubicada preferentemente en la capital provincial, Huesca.

El cambio de los usos del suelo entre 1957 y 1990 ha sido considerable (Figs. 3 y 4). La agricultura de 1957 muestra los rasgos típicos de uso tradicional del suelo en el interior de la Península Ibérica. El reparto de superficies entre pasto/monte bajo, cereales y vid es casi igual. Hasta 1990, la superficie de pastoreo aumenta considerablemente, hasta alcanzar algo más de la mitad de la superficie aprovechada. El cereal mantiene su importancia, mientras que la vid desaparece y se desarrolla el almendro en los últimos años.

Las razones principales para estos cambios pueden encontrarse, además, en la desaparición de mano de obra, en la orientación de la producción de los mercados regionales hacia otros internacionales, hecho que se ha acentuado con la política de subvenciones de la Unión Europea.

Los cambios que han tenido lugar pueden resumirse de la siguiente manera:

a.- La estructura social y económica del pueblo se ha visto reducida al mínimo.

b.- Todo el ámbito pirenáico ha de ser visto como área de recreo o retiro de jubilación, y no como zona de actividad agrícola. 


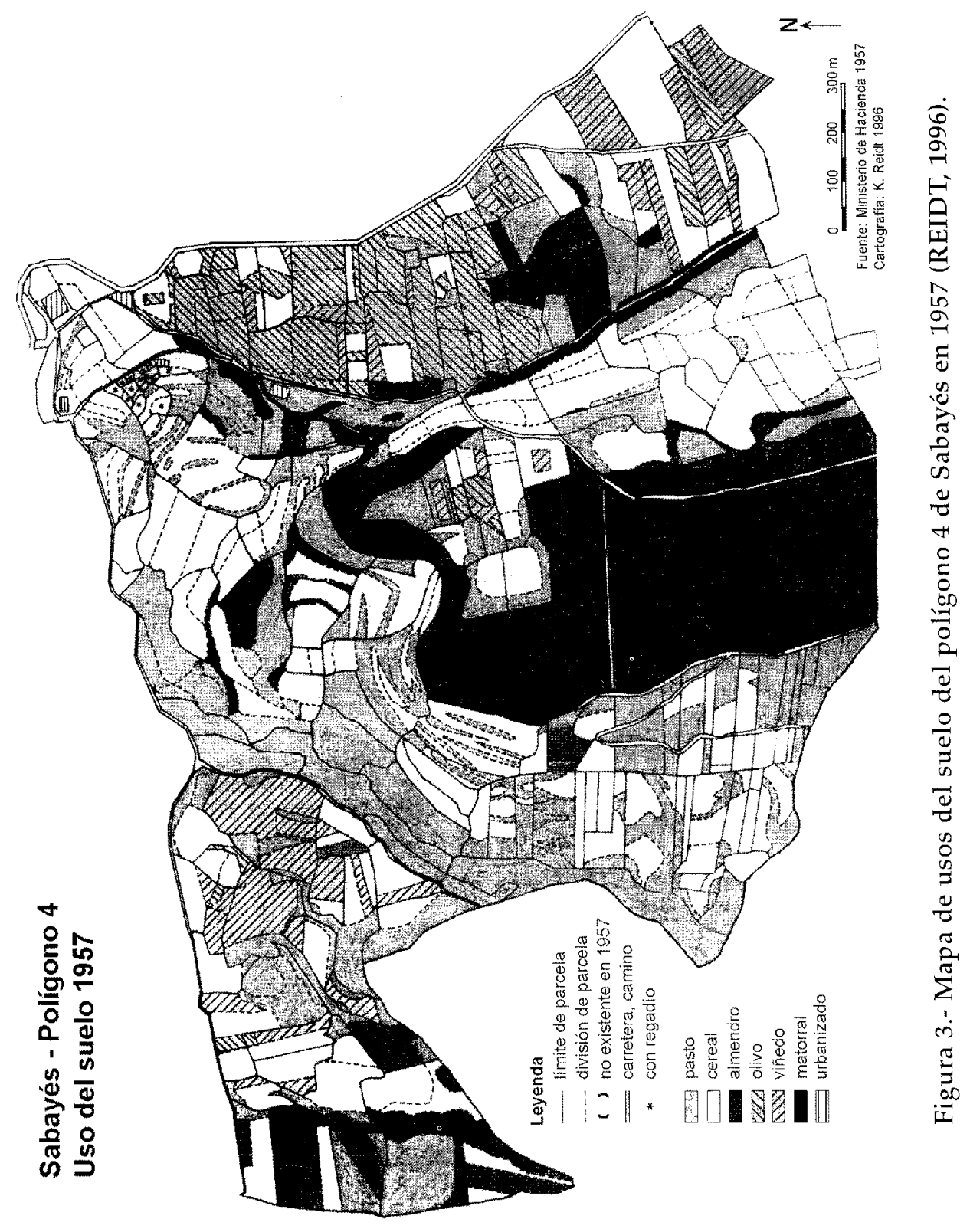




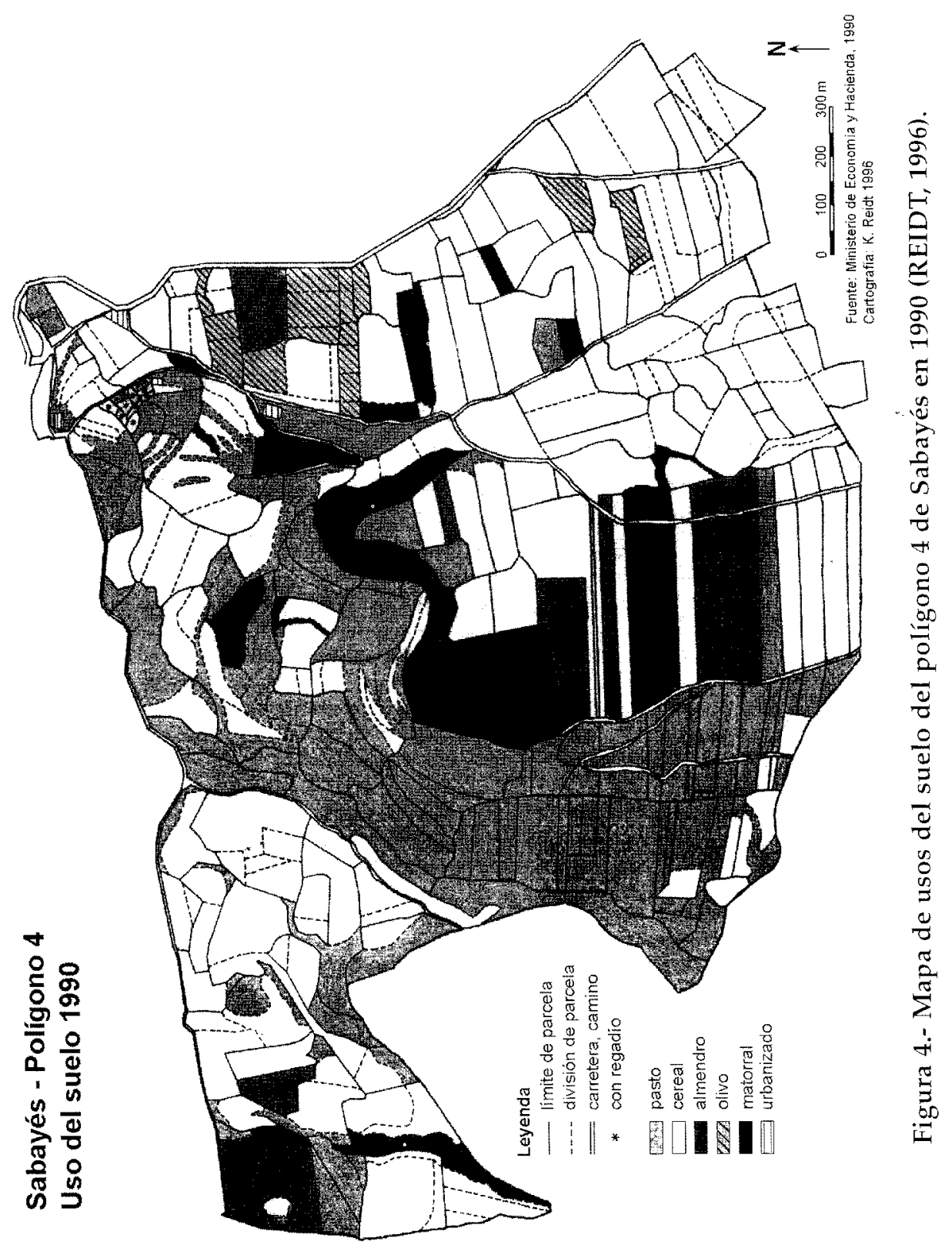


Por un lado, el pueblo es restaurado por la población emigrada hacia centros industriales y de servicios, pero la agricultura no es activada; en segundo lugar, la continuidad de las explotaciones agrícolas es difícil por el bajo interés de la población, basado parcialmente en las duras condiciones de trabajo, y por último, la demanda de zonas de recreo aumenta a causa del proceso de industrialización y el incremento de la concentración en núcleos urbanos.

c.- La creciente importancia de la política agraria en la Unión Europea.

\section{Clases biogeográficas y morfogenéticas}

Se presentan los resultados obtenidos en un campo abandonado en 1991 tras asignar valores a la retícula, definida en el apartado metodológico, en dos muestreos llevados a cabo en octubre de 1995 y abril de 1996. Las imágenes creadas partiendo de estas clasificaciones dejan reconocer fácilmente que, tras 5 años sin labor, la vegetación rara vez supera la clase $1(0-5 \%)$. Las zonas de mayor cobertura se encuentran en 1 a parte superior del área, en forma de manchas extensas de Hordeum murinum.

La morfogénesis clasificada durante ese muestreo está dominada por "erosión difusa ligera". La mitad inferior del área test muestra retículas de"erosión difusa fuerte" encontrando tres surcos de hasta $20 \mathrm{~cm}$ de profundidad. Se puede observar, además, algún proceso de acumulación en el borde inferior del área de muestreo. E1 muestreo efectuado en abril de 1996, manifiesta una situación diferente. Las fuertes precipitaciones del invierno han provocado el crecimiento de la vegetación por toda el área muestreada, dominando las clases $2(5-30 \%)$ y $3(30-60 \%)$. La morfogénesis se h a visto modificada ganando terreno la clase 3, "erosión difusa fuerte", y aumentado las áreas con clase 5, "acumulación", en la parte inferior del área test. Las zonas con una cubierta vegetal más densa no muestran erosión (clase 1) (Figs. 5 y 6).

Partiendo de estas clasificaciones pueden calcularse los cambios y visualizarse de forma parecida. Resumiendo, las observaciones de los dos muestreos denotan in aumento de actividad erosiva (de clase 2, "erosión difusa ligera", a clase 3, "erosión difusa fuerte") y un aumento de las zonas con acumulación (clase 5) en las áreas de mayor cubierta vegetal.

\section{Monitoring}

Basándose en las series de imágenes tomadas durante 2 años, se pueden documentar y cuantificar los procesos geomorfológicos, al igual que el desarrollo de la cubierta vegetal en un afluente de la Val de las Lenas (Valle del Huerva, Zaragoza). 

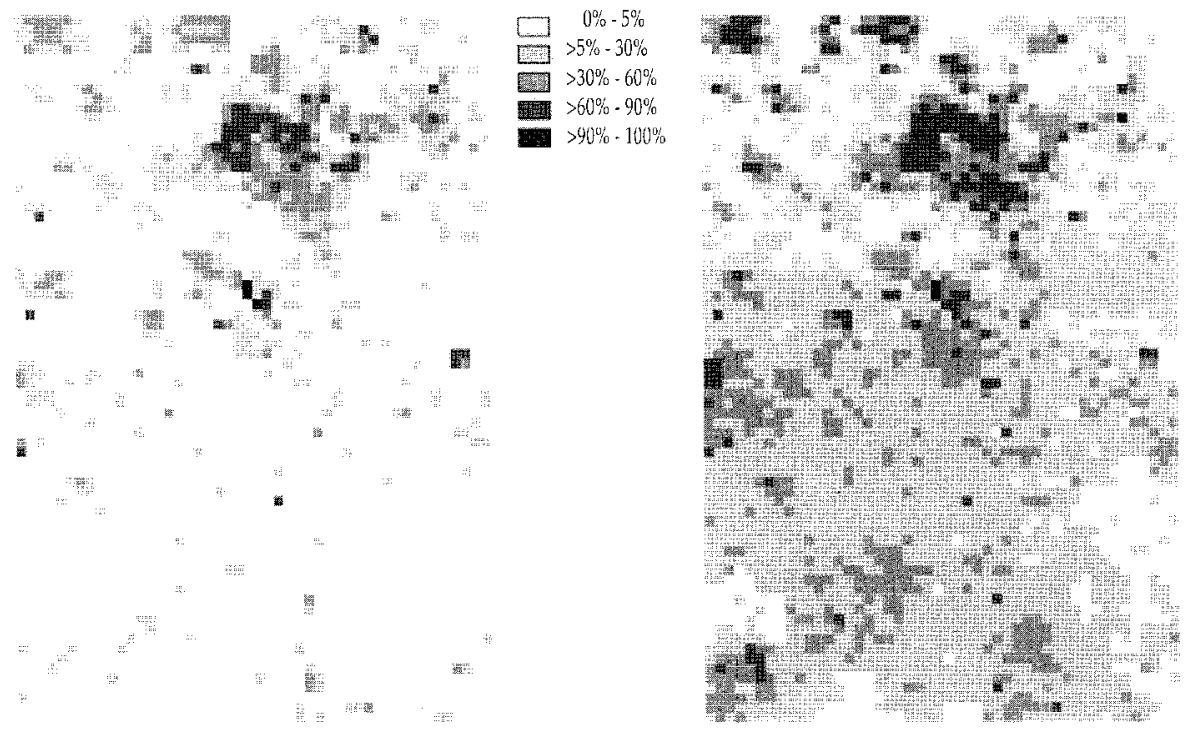

Figura 5.- Clases de cubrimiento vegetal en octubre de 1995 (izda.) y abril de 1996 (dcha.) en un campo abandonado hacía 5 años.
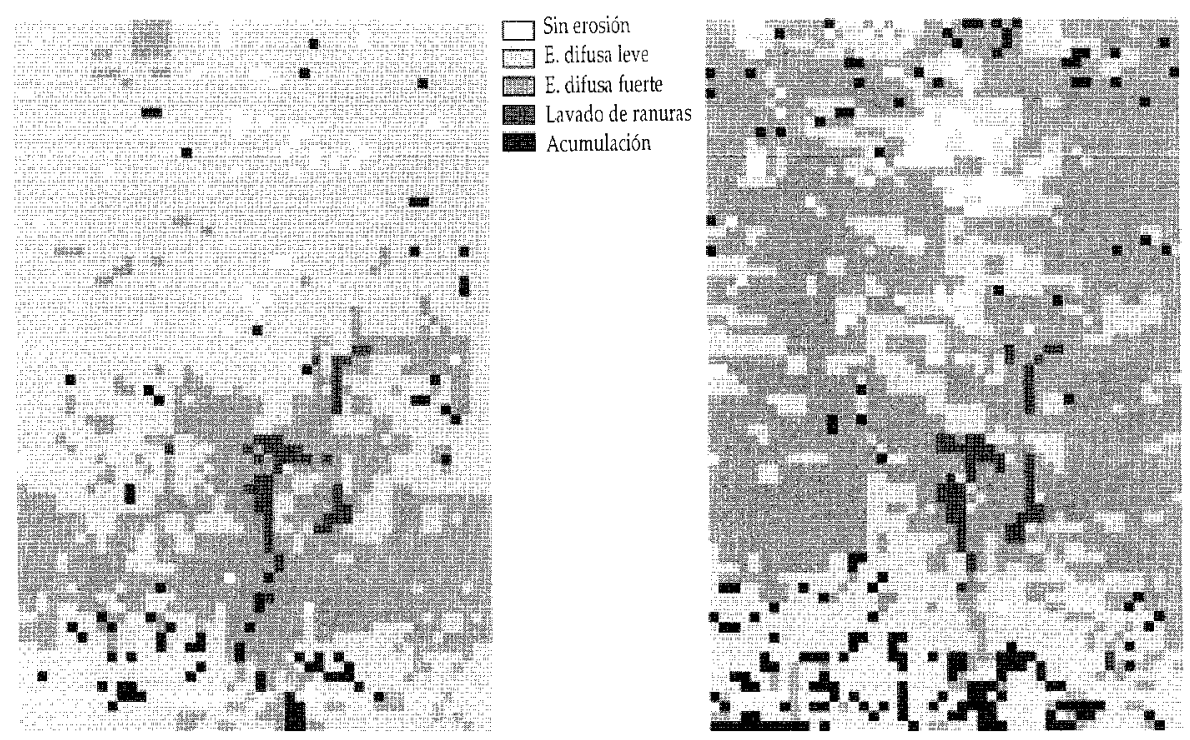

Figura 6.- Clases morfogenéticas en octubre de 1995 (izda.) y abril de 1996 (dcha.) en un campo abandonado hacía 5 años. 


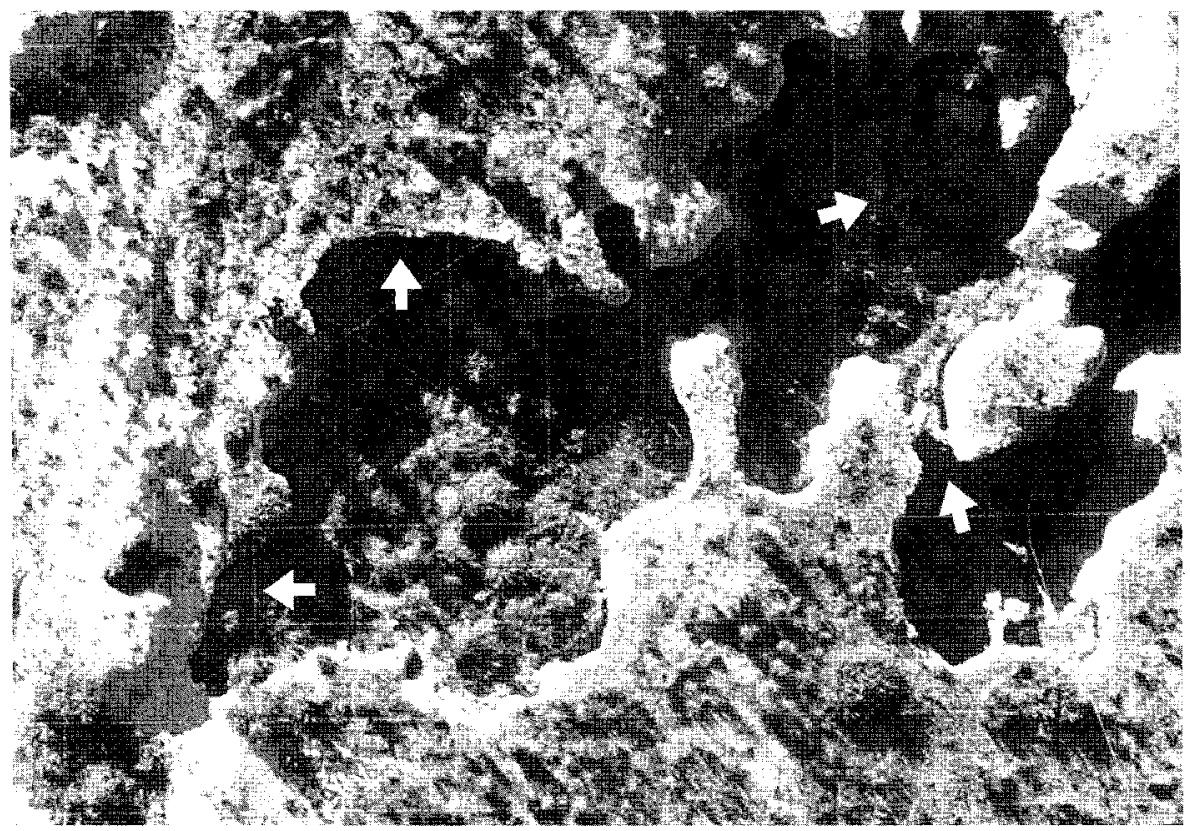

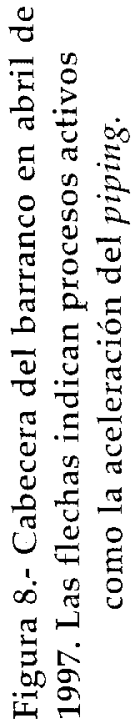
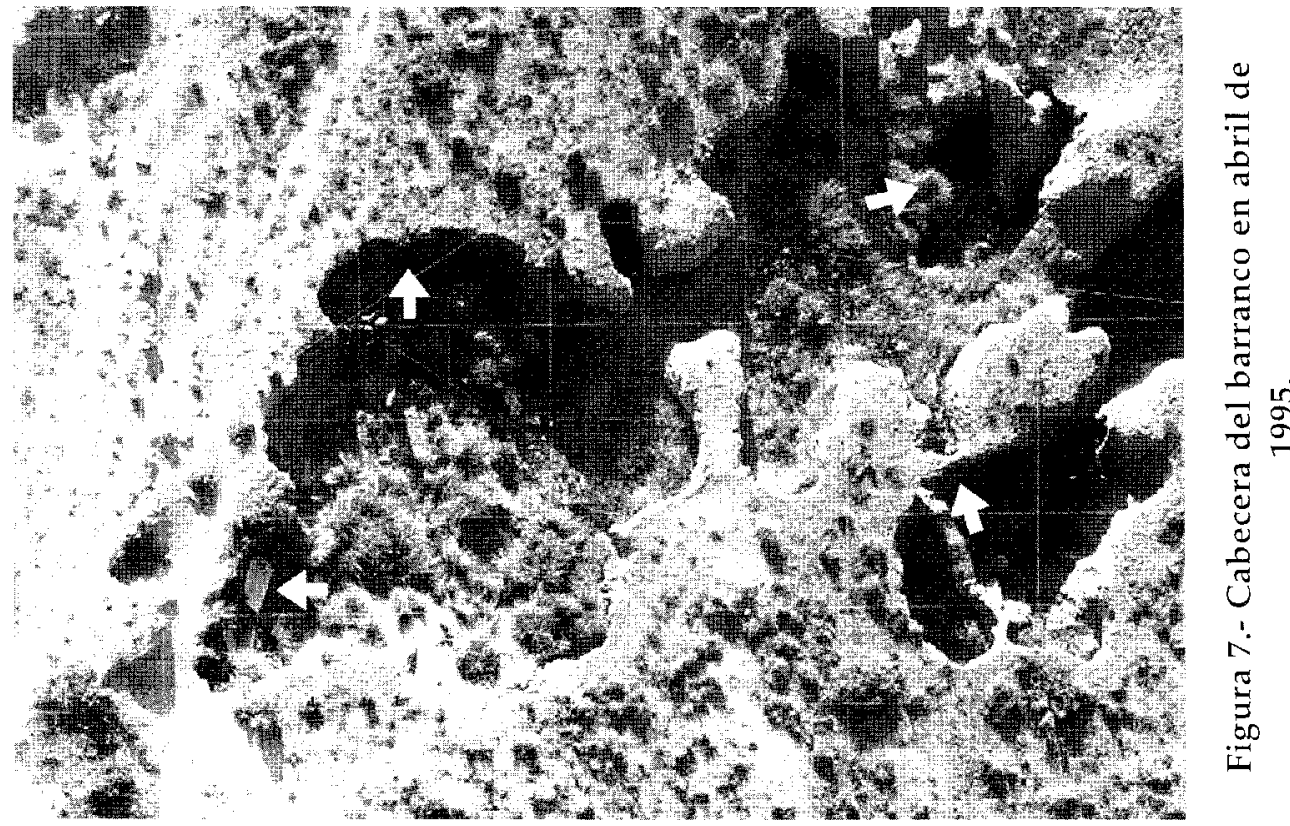


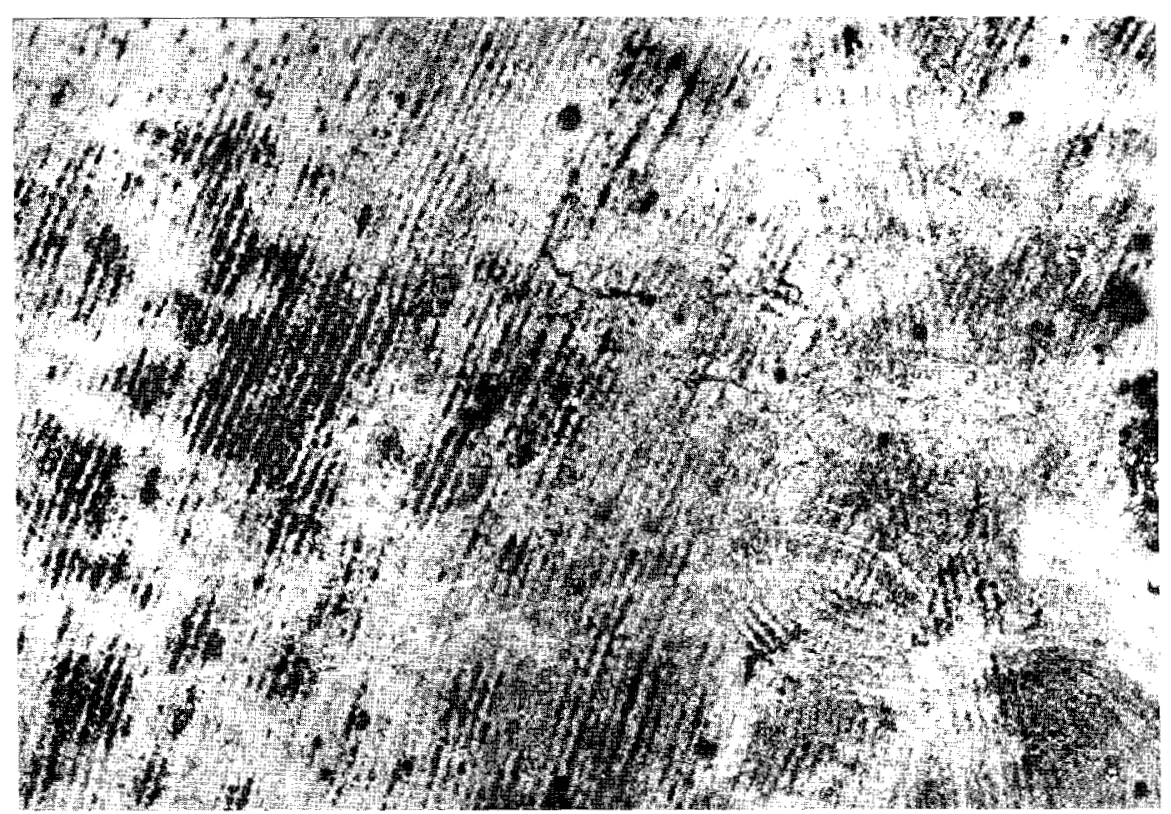

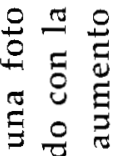

艺 $\Xi$

$\approx \pi$

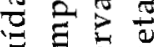

इ 0 ठ

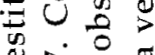

수

इ $\stackrel{2}{2}$

$\stackrel{0}{*} \approx$

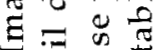

‥ 능 응

D

ก ช

OD

些完

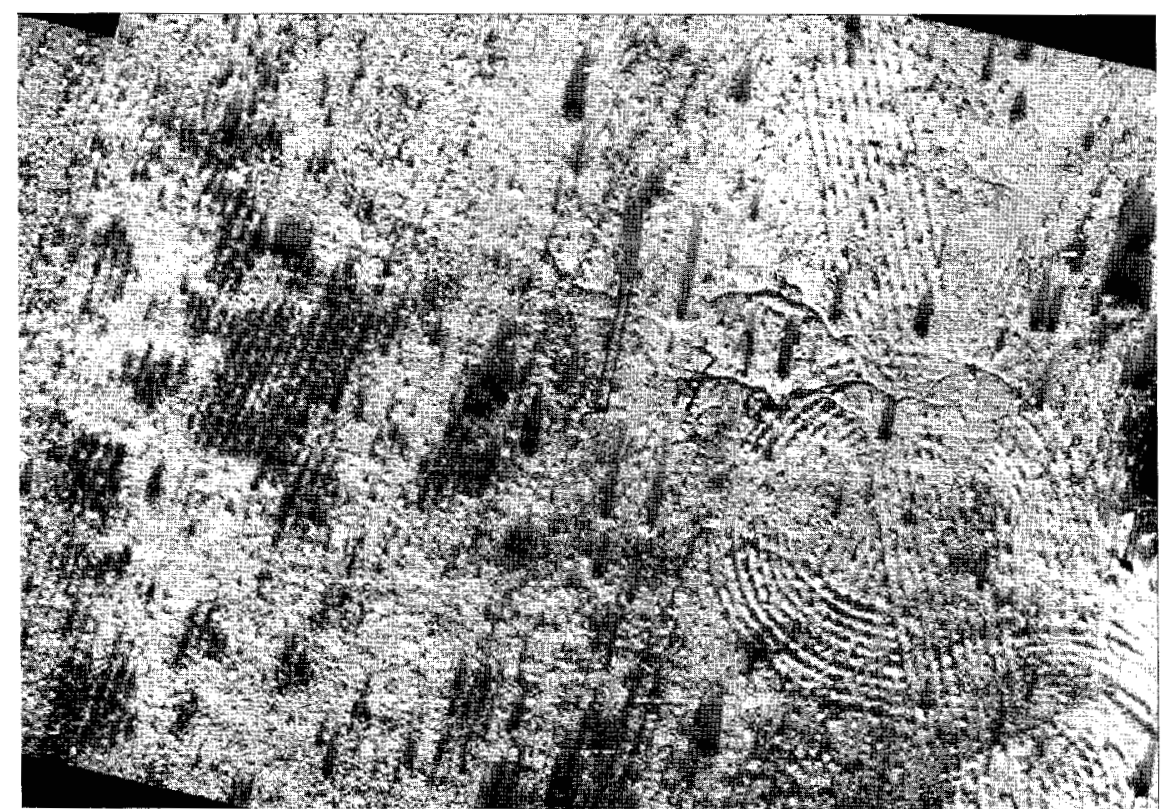

$\stackrel{0}{0}$

E

巳

党

胥

$\exists \sum \dot{R}$

눈

$=2$

$\frac{\infty}{0}$

导:

1. 을

a

전

3

记雚 
Entre octubre de 1995 (Fig. 7) y abril de 1997 (Fig. 8) se puede observar, por ejemplo, el desprendimiento de paneles en las paredes del barranco y el aumento del piping.

Otro ejemplo que demuestra las posibilidades de la metodología de tratamiento digital está basado en el área de trabajo MDH1, en el término municipal de María de Huerva (Zaragoza), aplicada a un campo sin cultivar desde hacía unos 5 años. La imagen digital (Fig. 9) tomada en octubre de 1995, está restituída con una resolución de $2,5 \mathrm{~cm}$. La estructura del campo, escasamente cubierto de vegetación, está claramente determinada por los surcos de la maquinaria agrícola. La imagen de abril de 1996 (Fig. 10) muestra un aumento importante de la vegetación, que acentúa la estructura de los surcos. Esto hace suponer que estos sirven de vías para la entrada de agua, así como de colectores para semillas, de modo que la vegetación puede desarrollarse mejor; el mapa de la estructura de surcos fue elaborado mediante análisis Fourier y filtro de bordes (Fig. 11).

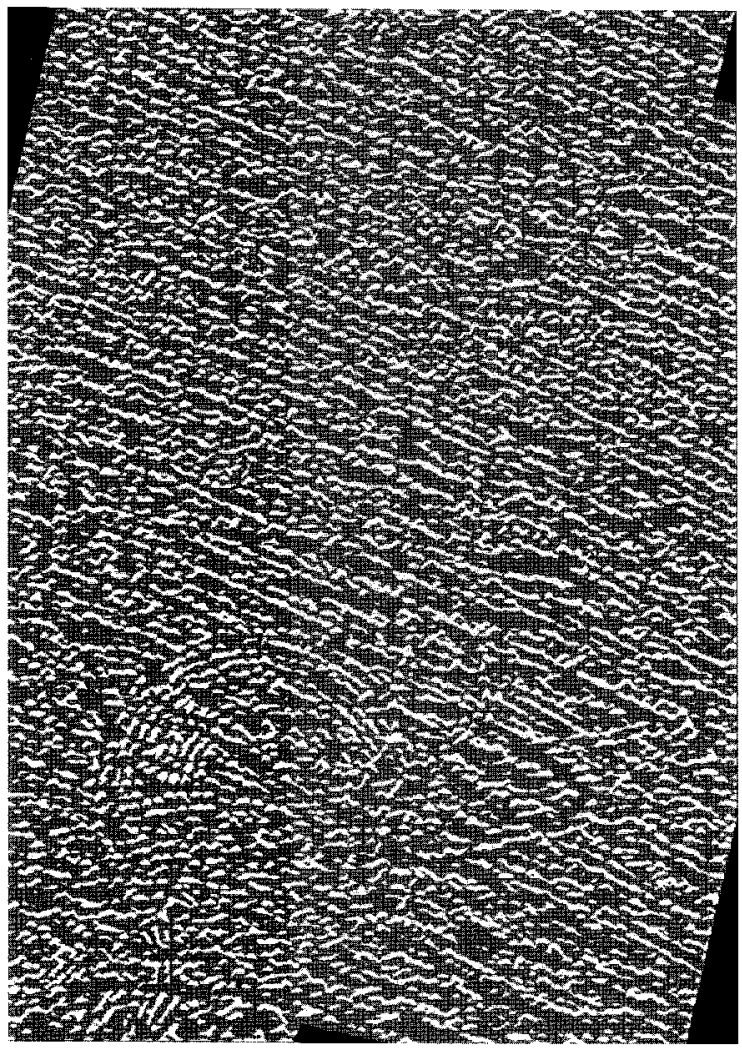

Figura 11.- Imagen elaborada mediante transformación Fourier y alisamiento de bordes a base de las fotos aéreas (se puede observar la estructura en surcos). 
El cálculo de la evolución de la vegetación confirma los resultados, ya que entre 1995 y 1996 la cubierta vegetal aumentó en los surcos um 21\%, mientras que en las restantes zonas lo hacía solamente en un $16,5 \%$.

\section{Estudio de los suelos}

Hasta ahora, el estudio de los suelos se ha limitado a un primer muestreo en el campo y un análisis químico e hidráulico de los perfiles.

Todos los suelos estudiados, excepto aquellos localizados en zonas que no han sido labradas, muestran en su morfología signos de labor, al igual que signos de erosión, deducidos de de la aparición de horizontes $\mathrm{Ap}$, que rara vez superan espesores de más de $10 \mathrm{~cm}$. El enraizamiento no excede $\operatorname{los} 50 \mathrm{~cm}$ de profundidad y es, salvo en formaciones de cesped en Bentué de Rasal, leve o mediano. Todas las áreas fuera de la Depresión del Ebro muestran una pedregosidad que llega a alcanzar el 50\%.

Como era de esperar, las cantidades de nutrientes difieren considerablemente entre los suelos de la Depresión del Ebro y el resto. La salinidad del suelo, especialmente de la zona enraizada, alcanza en María de Huerva niveles superiores a $1 \%$. Tan sólo un perfil en el campo abandonado más recientemente muestra cantidades en torno a $0,5 \%$; la salinidad en las zonas restantes es casi nula.

En María de Huerva también se encuentran cantidades considerables de nutrientes, aunque los niveles de fosfatos de los horizontes enraizados son relativamente bajos, de modo que este nutriente puede ser un limitante para la germinación de todo tipo de vegetación, ya que otros como el Magnesio y el Potasio parecen ser suficientes.

Las demás zonas de trabajo muestran características de baja capacidad productiva del suelo, ya que los valores obtenidos son bajos.

El pH del suelo es a lo largo del transecto paisajístico mas o menos neutro, con tendencias hacia la alcalinidad en María de Huerva y hacia una ligera acidificación en el resto de las áreas.

Las conductividades de los suelos muestran valores entre altos y medianos ( $\mathrm{Kf}$ desde $1,0 * 10^{-2}$ hasta $6,5 * 10^{-4} \mathrm{~cm} / \mathrm{s}$ ). La capacidad de campo disponible (pF18 - pF 4,2 ) alcanza un promedio de $22 \%$ del volumen (máx. $28,8 \%$, mín. $16,8 \%$ ). 
Tabla 1.- Datos medios de María de Huerva.

\begin{tabular}{|c|c|c|c|c|c|c|}
\hline & $\begin{array}{c}\mathrm{pH} \\
\left(\mathrm{CaCl}_{2}\right)\end{array}$ & $\begin{array}{c}\mathrm{P}_{2} \mathrm{O}_{5} \\
(\mathrm{mg} / \mathbf{1 0 0 g})\end{array}$ & $\begin{array}{c}\mathrm{K}_{2} \mathrm{O} \\
(\mathrm{mg} / \mathbf{1 0 0 g})\end{array}$ & $\begin{array}{c}\mathbf{M g} \\
(\mathrm{mg} / 100 \mathrm{~g})\end{array}$ & $\begin{array}{c}\mathbf{N} \text { Tot } \\
(\%)\end{array}$ & $\begin{array}{c}\text { Sales } \\
(\%)\end{array}$ \\
\hline mín & 6,6 & 1 & 7 & 3 & 0,01 & 0,42 \\
\hline máx & 8,3 & 40 & 46 & 350 & 0,36 & 1,85 \\
\hline media & 7,7 & 9 & 18 & 71 & 0,1 & 1,1 \\
\hline
\end{tabular}

Tabla 2.- Datos medios de Sabayés.

\begin{tabular}{|c|c|c|c|c|c|c|}
\hline & $\begin{array}{c}\mathrm{pH} \\
\left(\mathrm{CaCl}_{2}\right)\end{array}$ & $\begin{array}{c}\mathrm{P}_{2} \mathrm{O}_{5} \\
(\mathrm{mg} / \mathbf{1 0 0})\end{array}$ & $\begin{array}{c}\mathrm{K}_{2} \mathrm{O} \\
(\mathbf{m g} / 100 \mathrm{~g})\end{array}$ & $\begin{array}{c}\mathrm{Mg} \\
(\mathrm{mg} / 100 \mathrm{~g})\end{array}$ & $\begin{array}{c}\mathrm{N} \text { Tot } \\
(\%)\end{array}$ & $\begin{array}{c}\text { Sales } \\
(\%)\end{array}$ \\
\hline mín & 7,4 & 1 & 3 & 5 & 0,02 & 0,04 \\
\hline máx & 7,7 & 1 & 8 & 6 & 0,11 & 0,06 \\
\hline media & 7,6 & 1 & 5 & 5 & 0,05 & 0,05 \\
\hline
\end{tabular}

Tabla 3.- Datos medios de Bentué de Rasal.

\begin{tabular}{|c|c|c|c|c|c|c|}
\hline & $\begin{array}{c}\mathrm{pH} \\
\left(\mathrm{CaCl}_{2}\right)\end{array}$ & $\begin{array}{c}\mathrm{P}_{2} \mathrm{O}_{5} \\
(\mathbf{m g} / \mathbf{1 0 0 g})\end{array}$ & $\begin{array}{c}\mathrm{K}_{2} \mathrm{O} \\
(\mathrm{mg} / \mathbf{1 0 0 g})\end{array}$ & $\begin{array}{c}\mathrm{Mg} \\
(\mathrm{mg} / \mathbf{1 0 0 g})\end{array}$ & $\begin{array}{c}\mathrm{N}_{\mathrm{T} \text { ot }} \\
(\%)\end{array}$ & $\begin{array}{c}\text { Sales } \\
(\%)\end{array}$ \\
\hline $\operatorname{mín}$ & 6,6 & 1 & 3 & 2 & 0,02 & 0,04 \\
\hline $\operatorname{máx}$ & 7,7 & 1 & 16 & 6 & 0,19 & 0,10 \\
\hline media & 7,3 & 1 & 6 & 3 & 0,10 & 0,06 \\
\hline
\end{tabular}

Tablas 1 a 3: Nutrientes en las Zonas de María de Huerva, Sabayés y Bentué de Rasal. Datos del LUFA Karlsruhe/Alemania; $\mathrm{pH}$ en $\mathrm{CaCl}_{2}, \mathrm{P}_{2} \mathrm{O}$ y $\mathrm{K}_{2} \mathrm{O}$ en extracto $\mathrm{CAL}$, Mg extraido en $\mathrm{CaCl}_{2}, \mathrm{~N}$ ignición en analizador, sales solubles por CE extracto 1:10. 


\section{Estudio de costras edáficas}

El estudio de las costras edáficas ha mostrado grandes diferencias estructurales en relación con la edad de su formación. Las más recientes muestran capas de sedimentación y hay en las zonas de granulometría más gruesa una estructura de placas, que no alcanza gran profundidad, relacionada con los procesos de humectación/secado. Las costras antiguas de los surcos tienen una estructura de placas incluso en las partes más profundas de las muestras. Además, se puede observar una cierta estructura vesicular, debido a que durante los procesos de hinchamiento y retracción queda aire atrapado en el suelo (Fig. 12).

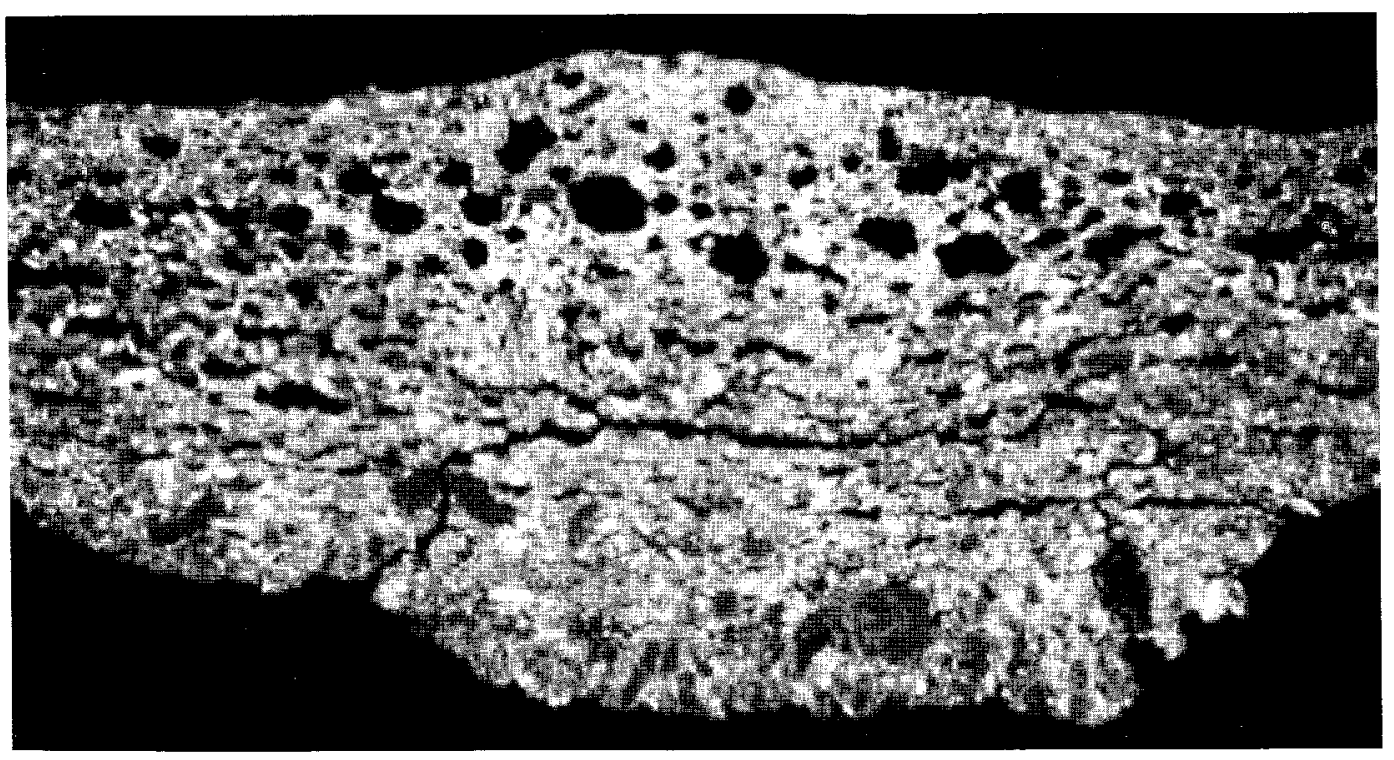

Figura 12.- Costra edáfica de un campo abandonado hace seis años en María de Huerva.

La estructura de las costras en los abanicos de sedimentación es similar. Estas costras forman una estructura alternante de capas de estructura vesicular y de capas de placas, debida a la aportación periódica de material. En los periodos de inactividad se forma la estructura ya conocida de los surcos, que después es cubierta por una nueva capa de material erosionado.

Sobre los recientes terrones levantados por las labores agrícolas no se observan costras. Sólo al cabo del tiempo, con numerosas precipitaciones, se forman esta clase de estructuras, de menor grosor que en los surcos, debidas al impacto de las gotas en el suclo. 
La formación de estructura vesicular requiere algunos años, pudiendo deducirse de ello que en ese tiempo el campo no sufre erosión difusa de importancia. Al menos, así es en los surcos y en los abanicos de sedimentación.

Las costras de los terrones, que deben su formación al impacto de la lluvia, se forman con más rapidez, pero son más débiles. Es difícil cuantificar el grado de erosión, pero las observaciones indican que con la desaparición tras un periodo de pocos decenios de la estructura de surcos y terrones, en éstos dominan procesos erosivos de mayor importancia.

Los experimentos de infiltración y de simulación de lluvia no permiten establecer diferencias entre las diversas costras, pero sí se puede observar que éstas, en general, reducen la infiltración, aumentan la escorrentía y a la vez protegen el suelo de la erosión. Esto sucede sólo hasta un umbral en el que el aumento de escorrentía conlleva, bajo determinadas condiciones, un aumento rápido de la erosión lineal.

\section{Experimentos sobre la infiltración, la escorrentía y la erosión}

Los datos que se aportan como ejemplo del área de María de Huerva muestran diferencias significativas entre un campo abandonado hace unos 60 años y otro hace tan sólo 5 años. La infiltración en este último arroja valores entre 7 y $18 \mathrm{~cm} / \mathrm{min}$, considerablemente más altos que en el primer campo mencionado, donde alcanza valores entre 1 y $6 \mathrm{~cm} / \mathrm{min}$. Tras 10 minutos la infiltración en el campo de 5 años es de $7 \mathrm{~cm} / \mathrm{min}$, mientras que en el de 60 años es de $2 \mathrm{~cm} / \mathrm{min}$; estos valores se basan en la reducción de la porosidad por falta de labor y el intenso pastoreo con ovejas y cabras.

Los experimentos con el simulador de lluvia muestran las diferencias entre los dos campos estudiados con mucha más claridad. En el campo abandonado más recientemente los valores de escorrentía, de material sólido y de material disuelto se mantienen constantes durante todo el ejercicio de simulación; en cambio, estos valores se incrementan considerablemente tras los primeros $15 \mathrm{mn}$ de precipitación en el campo abandonado hace 60 años. Al final del experimento en el campo abandonado hace seis décadas se suman cantidades tres veces más altas de material sólido erosionado y el doble de material disuelto. Estos datos puntuales son difíciles de extrapolar a superficies más extensas, pero sirven como una primera aproximación. 


\section{CONCLUSIONES}

En este artículo se han presentado ejemplos para ilustrar parcialmente los métodos y las posibilidades del proyecto EPRODESERT, donde se combinan métodos de investigación propios de las ciencias sociales y naturales con la teledetección, enfocados todos ellos hacia el estudio de los procesos naturales.

El sistema de monitoring de clasificación, combinado con la toma regular de fotos aéreas es adecuado para describir y cuantificar los procesos erosivos y 1 a evolución de la masa vegetal en las áreas de estudio.

Se han podido comprobar diferencias considerables en el comportamiento de los campos de diferente edad de abandono en relación con los agentes erosivos. Los primeros experimentos demuestran que la distribución espacial de las costras edáficas y su estructura son determinantes para el comportamiento del suelo en cara a la erosión.

El estudio detallado de las costras y de su génesis es fundamental para el entendimiento de su influencia en la morfogénesis.

El proyecto EPRCDESERT ha seguido muy de cerca la evolución de los campos abandonados bajo diferentes condiciones climáticas y ha conseguido hasta ahora identificar y caracterizar los procesos dominantes.

En las próximas campañas se intensificará el estudio de las bases físicas y ecológicas de las áreas estudiadas, así como de los procesos dominantes. Se continuarán los estudios experimentales enfocándolos a cuestiones más específicas, como el comportamiento de la escorrentía y la infiltración bajo matorral de diferente porte o sobre diferentes costras edáficas y líquenes. Nuevos experimentos de erosión eólica complementarán el estudio; para verificar la magnitud de los procesos eólicos en la zona, se han instalado varias trampas de sedimento.

El estudio de la química e hidrología de los suelos en las diferentes zonas llevará a una valoración de la capacidad de su carga ecológica. Se establecerán modelos para simular la dinámica del agua y, de forma más restringida, de los nutrientes bajo diferentes condiciones climáticas. Con estas informaciones se pretende entender la dinámica de la sucesión vegetal en los campos tras del abandono. Esta dinámica y la fisionomía de la vegetación serán puestas directamente en relación con la morfogénesis. 
Para la consecución de todos estos objetivos se seguirá con la clasificación regular del las áreas de trabajo y con la toma paralela de fotos aéreas con el "blimp". Esto permitirá tener un seguimiento preciso de los procesos y de los cambios morfogenéticos durante los últimos años.

\section{Agradecimientos}

Agradecemos el apoyo y las muchas ideas aportadas por parte de miembros del Dpto. de Geografía y Ordenación del Territorio de la Universidad de Zaragoza, especialmente por los Dres. Echeverría y de la Riva, así como por el Dr. García-Ruiz del Instituto Pirenaico de Ecología (CSIC) en Zaragoza. En general damos las gracias a todos aquellos que nos prestan su apoyo y atención en nuestros lugares de trabajo.

El proyecto está financiado por la DFG (Deutsche Forschungsgemeinschaft) y, en parte, por el DAAD (Deutscher Akadenischer Austauschdienst).

\section{BIBLIOGRAFÍA}

ETCH, A. (1996): Infiltrationsmessungen auf Testflïchen in Aragonien/Spanien mit dem Doppelringund dem Einfaclininginfiltrometer. Tesis de fin de carrera, inédita, Univ. Freiburg, 88 p.

HIRT, U. (1997): Untersuchungen an Schlämmknusten auf Ackerbrachen in Aragón/Spanien mithilfe von Dimnschliffen. Unveröff. Tésis de fin de carrera, inédita, Univ. Frankfurt.

MÄCKEL R. \& RIES. J.B. (1996): "Geomorphologische Untersuchung zur Degradation landwirtschaftlicher Nutzflächen in María de Huerva". APT-Reports, 5, 29-59, Freiburg.

MARZOLFF, I. \& RIES, J.B. (1997): "35-mm photography taken from a hot-air blimp: Monitorinbg processes of land degradation in Northern Spain". In: Proceedings of the First North Americnin Symposium on Small Format Aerial Photograply, October 14-17, 1997, Cloquet, Minnesota, USA. ASPRS Technical Papers, 91-101.

REIDT, K. (1996): Sozioökonomische Rahmenbedingungen des Landnutzungsioandels in Aragón/Spanien - dargestellt an zwei aragonesischen Siedlungen. Tesis de fin de carrera, Univ. Freiburg, inédita, $91 \mathrm{p}$.

RIES, J.B. (1996): "Landnutzungswandel und Geomorphodynamik in Spanien - eine Einführung in des Projekt EPRODESERT"; In Mäckel R., Ries J.B. \& Marzolff, I. (Eds.): Lnndnutzungsivande? und Univeltverändermugen in Spanien. Tagungsberichte des Arbeitstreffens 11.07-13.07.1996 in Freiburg i. Br., APT Reports, 7, 3-16; Freiburg.

RIES, J.B. \& MARZOLFF, I. (1997): "Identification of sediment sources by large-scale aerial photography taken from a monitoring blimp."Physics and Chenistry of the Earth. Procedings of the Eiropean Geoplysical Society, XXI General Ássembly The Hague, The Netherlands, 6-10 May. 
WEISE, M. (1996): Beregnungsversuche mit einer mobilen Kleinberegnungsanlage auf ausgesuchten Brachflächen in Aragonien/Spanien. Tesis de fin de carrera, Univ. Freiburg, inédita, $110 \mathrm{p}$. 